\title{
Enfisema subcutáneo no infeccioso en mano: reporte de un caso
}

\section{Non-infective subcutaneous emphysema of the hand: case report}

\author{
Paul Jesús Tejada-Llacsa, ${ }^{1,2, a}$, Wagner Cruz Pioquinto, \\ ${ }^{1}$ Facultad de Medicina, Universidad Nacional Mayor de San Marcos, Lima, Perú. \\ ${ }^{2}$ Asociación para el Desarrollo de la Investigación en Ciencias de la Salud (ADIECS), Lima, Perú. \\ ${ }^{3}$ Hospital I Marino Molina Scippa, EsSalud, Lima, Perú \\ ${ }^{a}$ Interno de medicina; ${ }^{b}$ Médico Cirujano.
}

\begin{abstract}
Resumen
El enfisema subcutáneo de causa no infecciosa se presenta raras veces. Debido a la importancia de discernir este cuadro de uno de causa infecciosa presentamos este caso. El paciente acudió al hospital por aumento de volumen en mano izquierda después de sufrir una cortadura en el quinto dedo con una barra de metal. Los análisis de sangre estuvieron dentro de rangos normales. Una radiografía mostró signos de enfisema subcutáneo. Se inició terapia antibiótica empírica. El enfisema remitió luego de 36 horas. Este caso es de interés debido a que es importante considerar cuadros de causa no infecciosa en el diagnóstico diferencial de enfisema subcutáneo de mano.
\end{abstract}

Palabras clave. Enfisema subcutáneo no infeccioso; Mano.

\section{Abstract}

Subcutaneous emphysema of noninfectious cause occurs rarely. We present this case due to the importance of discerning it from one with an infectious etiology. Our patient came to the hospital with increased volume in the left hand after suffering a cut on the fifth finger of that hand with a metal bar. Blood tests were within normal ranges. Signs of subcutaneous emphysema were noted in the hand X-ray. Empirical antibiotic therapy was initiated with improvement at 36 hours. This case is of interest to consider non-infectious causes in the differential diagnosis of hand emphysema.

Keywords. Subcutaneous emphysema; Hand.

\section{An Fac med. 2016;77(1):51-3 / http://dx.doi.org/10.15381/anales.v77i1.11553}

\section{INTRODUCCIÓN}

El enfisema subcutáneo es definido como la presencia de gas o aire en el plano del tejido subcutáneo. Existen muchas causas para este cuadro; sin embargo, la causa no infecciosa ocurre raras veces y suele presentarse después de un trauma ${ }^{(1)}$. Debido a la importancia de discernir este cuadro de uno de causa infecciosa reportamos a continuación un caso de enfisema subcutáneo de la mano.

\section{REPORTE DE CASO}

Paciente varón de 30 años natural de Lima, sin antecedentes de importancia, acudió a emergencia del Hospital Marino Molina Scippa con un tiempo de enfermedad de 3 horas. Refirió lesionarse el quinto dedo de la mano izquierda con el filo de una barra de metal. Inmediatamente nota un aumento de volumen, por lo que viene a emergencia del hospital. Al examen físico, el paciente se encontraba en buen estado general. Se observó una lesión de aproximada- mente $7 \mathrm{~mm}$ en el quinto dedo de la mano izquierda (figura 1), sin sangrado activo, limitación funcional ni signos de flogosis. A la palpación, se percibió crépitos desde la mano hasta el tercio distal del antebrazo izquierdo; no refirió dolor.

En las muestras de laboratorio se halló leucocitos $9260 \mathrm{mil} / \mathrm{mL}$, abastonados $0 \%$, segmentados 63\%, hemoglobina $14,4 \mathrm{~g} / \mathrm{dL}$, plaquetas $332 \mathrm{000/}$ $\mathrm{mL}$, glucosa $89 \mathrm{mg} / \mathrm{dL}$, urea $30 \mathrm{mg} / \mathrm{dL}$, creatinina $1,12 \mathrm{mg} / \mathrm{dL}$. 

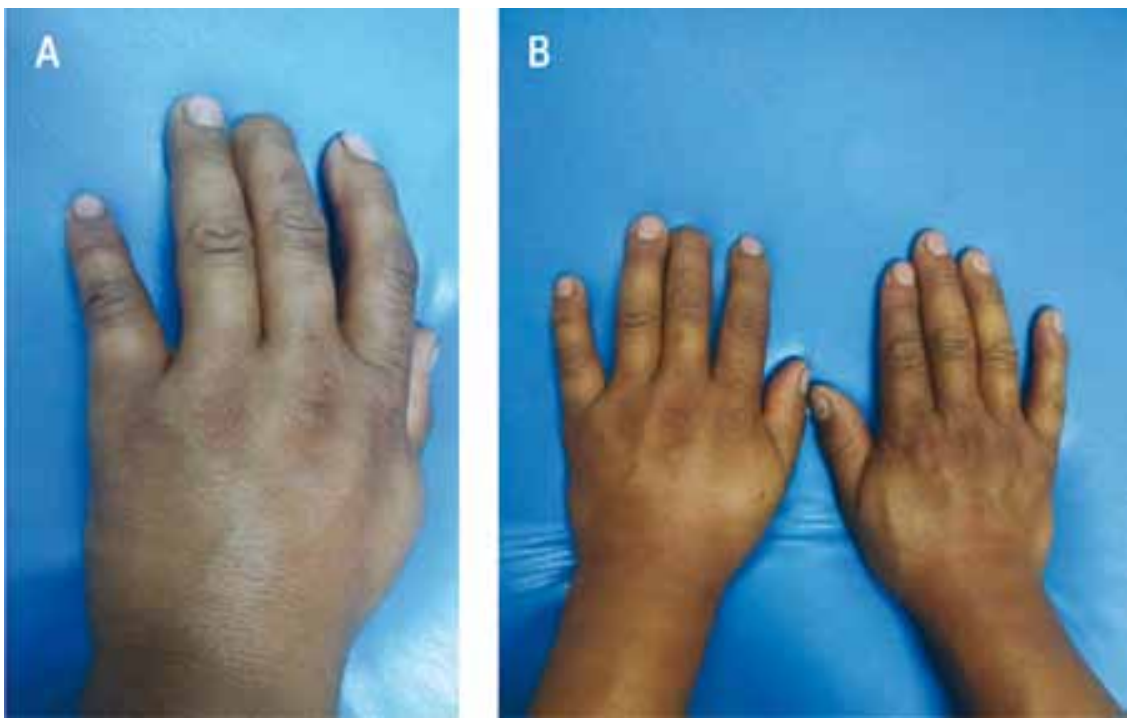

Figura 1. A: Se observa herida en quinto dedo de la mano izquierda. B: Comparativamente, hay un aumento de volumen en la mano izquierda.

En la radiografía de mano izquierda se observó enfisema subcutáneo (figura 2). El paciente recibió como terapia empírica cefazolina $1 \mathrm{~g}$ EV c/8 h. Luego de 36 h se observó una disminución

marcada de los crépitos y del volumen de la mano afectada. Al encontrarse estable y sin molestias, fue dado de alta con el diagnóstico de enfisema subcutáneo de causa traumática.
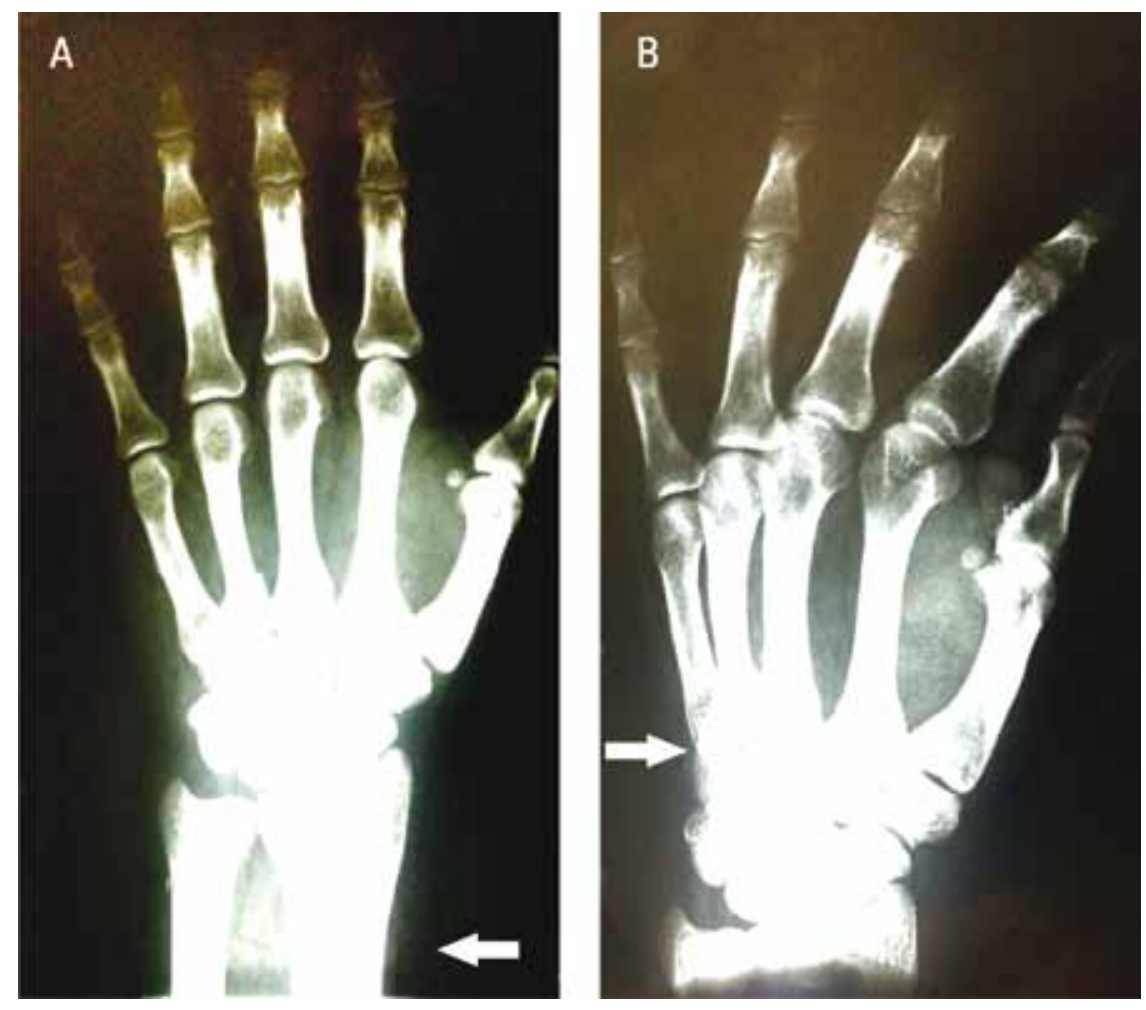

Figuras 2 A y 2B. Radiografias de mano izquierda con signos de enfisema subcutáneo.

\section{DISCUSIÓN}

El enfisema subcutáneo que afecta aisladamente a una extremidad es infrecuente ${ }^{(2)}$. Se le suele relacionar con infección por Clostridium, que ocasiona un cuadro de gangrena gaseosa acompañado de toxemia sistémica, crépitos y una extensa inflamación ${ }^{(3)}$. Cuando este tipo de enfisema no es de causa infecciosa, en algunas reportes lo denominan enfisema benigno ${ }^{(4)}$. Sin embargo, es importante mencionar que no siempre tienen un curso benigno, ya que necesitan incluso intervención quirúrgica ${ }^{(5)}$.

El mecanismo propuesto para explicar este enfisema es el de la válvula de esfera, de tal forma que el flujo de gas siga una sola dirección haciendo que se acumule en el tejido subcutáneo ${ }^{(6)}$. Este tipo de enfisema ha sido descrito en los siguientes casos: después de procedimientos quirúrgicos ${ }^{(7)}$, después de un traumatismo leve penetrante en herida ${ }^{(2)}$, injurias ocasionadas por inyecciones de alta presión ${ }^{(8)}$, lesiones por explosión, lesiones por espina ${ }^{\left({ }^{9}\right)}$, lesiones simples por abrasión o mordedura de insectos ${ }^{(10)}$.

Este tipo de enfisema suele remitir espontáneamente; sin embargo, en los reportes encontrados suelen dar terapia antibiótica ${ }^{(11,12)}$. Existen algunos casos en donde hubo necesidad de realizar debridamiento quirúrgico ${ }^{(10,12)}$. En el caso presentado, el cuadro remitió sin necesidad de procedimiento quirúrgico.

Finalmente, el enfisema subcutáneo no infeccioso debe ser pensado en los casos donde se encuentra gas en el tejido blando, especialmente si no hay signos de infección. Además, de acuerdo la bibliografía encontrada, se sugiere vigilar entre 24 y 48 horas mientras se comienza con antibioterapia empírica ${ }^{(5)}$.

\section{REFERENCIAS BIBLIOGRÁFICAS}

1. Verma S. Subcutaneous emphysema: a rarity in dermatology. J Eur Acad Dermatology Venereol. 2007;21:247-8. doi:10.1111/j.14683083.2006.01805.x. 
2. Fox a, Sheick H, Ekwobi C, Ho-Asjoe M. Benign surgical emphysema of the hand and upper limb: gas is not always gangrene--a report of two cases. Emerg Med J. 2007;24:798-9. doi:10.1136/ emj.2007.046755.

3. Lo SJ, Hughes J, Armstrong A. Non-infective subcutaneous emphysema of the hand secondary to a minor webspace injury. J Hand Surg Am. 2005;30:482-3. doi:10.1016/j.jhsb.2005.04.020.

4. Klein M, Szkrabko S, Rodriguez J, Payaslian S. Enfisema subcutáneo en mano y antebrazo por aire comprimido. Med (Buenos Aires). 2003;63:721-3.

5. Tiong WHC, Butt FS. Subcutaneous emphysema of the upper extremity following penetrating blackthorn injury to the wrist. J Plast Reconstr Aesthetic Surg. 2009;62:e29-32. doi:10.1016/j. bjps.2007.11.002.

6. Winshall JS, Weissman BN. Benign subcutaneous emphysema of the upper extremity. N Engl J Med. 2005;352:1357. doi:10.1056/NEJMicm040914.

7. Gamboa Vidal CA, Vega Pizarro CA, Almeida Arriagada A. Subcutaneous emphysema secondary to dental treatment: case report. Med Oral Patol Ora Cir Bucal. 2007;12:E76-8.

8. Pay AD, Crick A. Subcutaneous emphysema of a digit through a pre-existing puncture wound $\mathrm{Br} J$ Plast Surg. 1999;52:505-6. doi:10.1054/ bjps.1999.3115.

9. Butt M, Hird GF. Surgical emphysema of the dorsum of the hand. J Hand Surg Am. 1990;15 B:379-80. doi:10.1016/0266-7681(90)90028-3.

10. Onwochei VE, Kelly ME, Lyons R, Khan W, Barry KM. Benign subcutaneous emphysema: A case report with bite. Int J Surg Case Rep. 2015;9:89-91. doi:10.1016/j.ijscr.2015.02.039.

11. Clayton-Smith MA, Sivathasan N. A case of benign subcutaneous emphysema. Case Reports. 2014;2014:bcr2013202261-bcr2013202261. doi:10.1136/bcr-2013-202261.

12. Mink Van Der Molen AB, Birndorf M, Dzwierzynski WW, Sanger JR. Subcutaneous tissue emphysema of the hand secondary to noninfectious etiology: a report of two cases. J Hand Surg Am. 1999;24:63841. doi:10.1053/jhsu.1999.0638.
Articulo recibido el 7 de julio de 2015 y aceptado para publicación el 10 de noviembre de 2015.

Financiamiento: Autofinanciada.

Conflictos de interés: Los autores declaran no tener conflictos de interés.

\section{Correspondencia:}

Paul Jesús Tejada Llacsa

Dirección: Av. Gonzales Prada 719, Comas, Lima,

Perú

Teléfono: 977141199

Correo electrónico: paultejada24@gmail.com 